Division of Geological \& Geophysical Surveys

PUBLIC-DATA FILE 94-30B

\title{
ELECTRONIC FILE OF
}

GEOCHEMICAL TRACE-ELEMENT DATA FOR STREAM SEDIMENT SAMPLES COLLECTED IN THE CIRCLE MINING DISTRICT, 1983

by

M.A. Wiltse, P.A. Mctz, M.S. Robirson, and D.S. Pinney

April 1994

THIS REPORT HAS NOT BEEN REVIEWED FOR

TECHNICAL CONTENT (EXCEPT AS NOTED IN TEXT) OR FOR CONFORMITY TO THE EDITORIAL STANDARDS OF DGGS.

Released by

STATEOF ALASKA

DEPARTMENTOFNATURALRESOURCES

Division of Geological \& Geophysical Surveys

794 Universily Avenue, Suite 200

Fairbanks. Aluska 99709-3645 


\section{CONTENTS}

INTRODUCTION

ANALYTICAL METHODS 1

$\begin{array}{ll}\text { FILES } & 2\end{array}$

REFERENCES

$\begin{array}{ll}\text { APPENDIX } 1 & 4\end{array}$ 


\title{
GEOCHEMICAL TRACE ELEMENT DATA FOR STREAM SEDIMENT SAMPLES COLLECTED IN THE CIRCLE MINING, 1983
}

By

\author{
Milton A. Wiltse', Paul A. Metz ${ }^{2}$, Mark S. Robinson', and DeAnne S. Pinney'
}

\section{INTRODUCTION}

In the summer of 1983, the Mineral Industry Research Laboratory (MIRL) of the University of Alaska, Fairbanks conducted an extensive stream-sediment sampling program in the Circle mining district. More than 1,100 strean-sediment samples were collected from active stream channels at approximately 1/4mile spacing between sample sites (plate 1, Wiltse and others, 1994). The samples were analyzed for gold and six other trace elements by atonic absorption analysis of aqua-regia digests. These data were published by Metz (1984). Representative sliquots of the samples were archived at MIRL.

In 1993 the Alaska Division of Geological and Geophysical Surveys (ADGGS) began a coordinated geological, geophysical, and geochemical survey of the central part of the Circle mining district. The archived MIRL stream-sediment sample set provided a cost effective opportunity to generate a detailed district-wide data base stream-sediment geochemistry for this project. The samples had been carefully stored in plastic vials and sample locations were plotted on stable mylar base maps. These samples were submitted to Bondar-Clegg \& Company, Ltd. for reanalysis.

Although gold, arsenic, tungsten, and tin are elements of particular interest in the Circle mining district, modern multi-element analytical procedures provide data for a far greater range of elements. The data presented in Appendix 1 (Wiltse and others, 1994) represent analyses from two multi-element analytical procedures: instrumental neutron activation analysis (INAA) and inductively coupled plasma (ICP) spectrographic analysis.

\section{ANALYTICAL METHODS}

\section{Instrumental Neutron Activation Analysis}

\section{Data Charscteristics}

Neutron activation analytical data represent total analyses. That is, the reported concentrations include the total relative amount of the element in the sample regardless of the mineral phase in which it resides. For some elements this characteristic can be significant. Today, for example, the presence of gold is of interest regardless of whether it occurs as free gold or as sub-microscopic grains encapaulated in silicate minerals. Total analyses of tin, however, do not distinguish between refractory tin silicates, tin sulfides, or tin oxides.

\footnotetext{
${ }^{1}$ Alaska Division of Geological and Geophysical Surveys, Department of Natural Resources

${ }^{2}$ Mineral Industry Research Laboratory, University of Alaska-Fairbanks
} 
For some elements the lower limit of detection is higher for neutron activation analysis than it is for chemical digestion procedures. For example the lower INAA detection limit for zinc is 200 parts per million (ppm) but is 1 ppm for ICP or atomic absorption spectrographic (AAS) procedures.

\section{Inductively Coupled Plasma Spectrographic Analysis}

\section{Data Characteristics}

Inductively couple plasma spectrographic procedures provide a quick and inexpensive method of obtaining a broad range of trace-element data. Much of the data, however, are semi-quantitative. The significance of the data also is strongly dependent on the digestion procedures that are used to prepare the sample for analysis. Sample digestion methods for ICP analysis include a wide variety of wet chemical methods. Common total digestion methods include various borate fusion-acid digestion protocols and various kinds of multi-acid digestion. Partial sample decomposition is commonly accomplished with an aqua-regia digestion. None of the ICP wet chemical digestion procedures is free of data-compromising complications for all elements reported in this Public-Data File.

The ICP data in this Public-Data File were generated from aqua-regia digests of the minus-80-mesh fraction (finer than $0.177 \mathrm{~mm}$ ) of stream sediments. Therefore, many of the mineral phases in the samples have been only partially decomposed. Aqua-regia digests do, however, provide a good indication of trace elements: present in sulfide mineral particles; present in various precipitated coatings on mineral grains; and present as trace elements loosely bonded to clay minerals. Those elements for which the data are least quantitative have been indicated with an asterisk (*). In some cases alternative data exit in the results compiled from neutron activation analysis of the sample. In general, those results not marked by an asterisk in the column heading may be more useful for geological interpretations.

\section{FILES}

The disk accompanying this report includes two data files: 1) MIRL93E4.XLS is a Microsoft Ver, 4.0 Excel ${ }^{\star}$ spreadsheet file; 2)MIRL93TB.WX3 is a Lotus 1-2-3 ${ }^{\star}$ worksheet file. Either file will generate Appendix 1 of ADGGS Public-Data File 94-30A, Geochemical Trace-Element Data For Stream Sediment Samples Collected in the Circle Mining District, in spreadsheet format when read by a compatible spreadsheet program.

(17) Excel is a registered trademark of the Microsoft Corporation and Lotus 1-2-3 is a registered trademark of the Lotus Development Corporation. Use of product names does not constitute an endorsement of those products but is cited only for informational purposes. 


\section{REFERENCES}

Metz, P.A., 1984, Stream sediment sample analyses for the Circle Mining District, Alaska: Mineral Industry Research Laboratory Open-File Report 84-9, 51 p., 12 sheets.

Wiltse, M.A., Metz, P.A., Robinson, M.S., and D.S. Pinney, 1994, Geochemical trace-element data for stream sediment samples collected in the Circle Mining District, Alaska Division of Geological and Geophysical Surveys Public-Data File 94-30A, 88 p., 1 sheet. 


\title{
APPENDIX 1
}

\section{Concentration of trace elements in Circle mining district stream sediments collected in 1983}

\begin{abstract}
Samplo locations are stated in decimal degrees. INAA indicates analysis was by instrumental neutron activation analysis; ICP indicates analysis was by inductively coupled plasma spectrography; (*) denotes the procedure yields a partial or otherwise compromised analysis; ppb indicates reported values are stated in parts per million; ppm indicates the values are stated in parts per million; (-) indicates the element was not detected at a concentration equal to the absolute value of the amount reported.
\end{abstract}

